\title{
Association Between the Use of Thiazide Diuretics and the Risk of Skin Cancers: A Meta-Analysis of Observational Studies
}

\author{
Doosup Shin ${ }^{\mathrm{a}, \mathrm{g}}$, Eun Sun Lee ${ }^{\mathrm{b}}$, Joonseok Kim ${ }^{\mathrm{c}}$, Lucy Guerra ${ }^{\mathrm{a}}$, \\ Dayan Naik ${ }^{\mathrm{a}, \mathrm{d}, \mathrm{e}}$, Xavier Prida ${ }^{\mathrm{f}}$
}

\begin{abstract}
Background: Thiazide diuretics are among the most widely prescribed antihypertensive agents. Given their photosensitizing effects, however, there are concerns that they may increase the risk of skin cancers. In this meta-analysis, we investigated an association between the use of thiazide diuretics and the risk of skin cancers.
\end{abstract}

Methods: We identified studies by searching three electronic databases (PubMed, EMBASE, and the Cochrane Library) from their inception to October 30, 2017. Nine relevant observational studies (seven case-control and two cohort studies) were included in this study. Since included studies were unlikely to be functionally equal, pooled estimates were calculated using random-effects meta-analysis.

Results: The use of thiazide diuretics was associated with an increased risk of squamous cell carcinoma (adjusted odds ratio (aOR), 1.86; $95 \%$ confidence interval (CI), $1.23-2.80$ ) and marginally increased risk of basal cell carcinoma (aOR, 1.19; 95\% CI, $1.02-1.38$ ) and malignant melanoma (aOR, 1.14; 95\% CI, $1.01-1.29)$. In the subgroup analysis, hydrochlorothiazide or hydrochlorothiazide combination medications were significantly associated with squamous cell carcinoma without significant heterogeneity among studies (aOR, 2.04; 95\% CI, $1.79-2.33$; Higgin's I ${ }^{2}$ value $=0.0 \%$; Q-statistics $=$ 2.7 , $\mathrm{P}$ value $=0.445)$.

Manuscript submitted January 6, 2019, accepted February 19, 2019

aDepartment of Internal Medicine, University of South Florida Morsani College of Medicine, Tampa, FL, USA

bDepartment of Internal Medicine, Louise A Weiss Memorial Hospital, Chicago, IL, USA

'Division of Cardiovascular Disease, Department of Medicine, University of Alabama at Birmingham, Birmingham, AL, USA

${ }^{\mathrm{d} N e w}$ York Medical College, Valhalla, NY, USA

'Nova Southeastern University College of Osteopathic Medicine, Fort Lauderdale, FL, USA

fDepartment of Cardiovascular Sciences, University of South Florida Morsani College of Medicine, Tampa, FL, USA

'Corresponding Author: Doosup Shin, Department of Internal Medicine, University of South Florida Morsani College of Medicine, 17 Davis Blvd., Suite 308, Tampa, FL 33606, USA. Email: doosup87@gmail.com

doi: https://doi.org/10.14740/jocmr3744
Conclusions: Our results suggested that the use of thiazide diuretics may be associated with an increased risk of skin cancers. This association was most prominent between the use of hydrochlorothiazide or hydrochlorothiazide combination medications and the risk of squamous cell carcinoma. Further studies are needed to confirm these findings.

Keywords: Thiazide; Diuretics; Skin cancer; Meta-analysis

\section{Introduction}

Hypertension is a major global health issue due to its high prevalence, under-treatment, and significant cardiovascular complications [1, 2].The eighth Joint National Committee (JNC 8) guidelines recommend thiazide-type diuretics as firstline antihypertensive agents for all ethnicities [2]. Because they are effective, inexpensive, and relatively safe medications with long track records, thiazides are among the widely prescribed antihypertensive medications worldwide [3, 4]. In $2001-2010,22.4-27.6 \%$ of patients with hypertension in the USA were prescribed with thiazide diuretics or thiazide-combination medications [5].

Skin cancer is the most common malignancy in the USA and it was estimated that one in five Americans will develop skin cancer in their lifetime [6-8]. Notably, some reported thiazides to be photosensitizing agents that may trigger an abnormal skin response to ultraviolet (UV) light $[9,10]$. This response is mediated by UV-induced dissociation of chlorine substituent of thiazides which causes free radical reaction and the formation of reactive oxygen species (ROS) [11-13]. Studies have shown that drug-induced photosensitization of the skin and subsequent exposure to UV radiation increased the risk of skin cancers [14-16].Therefore, there is a concern that the use of thiazide diuretics may increase the risk of skin cancers [3]. Although several observational studies have investigated the association between thiazide medication use and skin cancers [17-27], the results are conflicting, and the exact relationship remains controversial. Therefore, we performed a meta-analysis of observational studies to investigate the association between the use of thiazides and the risk of skin cancers. 


\section{Materials and Methods}

\section{Search strategy}

This study was conducted according to the Meta-analyses Of Observational Studies in Epidemiology (MOOSE) guideline [28]. The MOOSE checklist is available in supporting information (Supplementary Table 1). PubMed, EMBASE, and the Cochrane Library were searched from their inception, respectively, until October 30, 2017. We used common keywords related to thiazide diuretics and skin cancers, including basal cell carcinoma (BCC), squamous cell carcinoma (SCC), and malignant melanoma (MM), without language restriction. The detailed search terms are described in supporting information (Supplementary Method). We also reviewed the bibliographies of relevant articles to locate additional publications. Only studies published in journals were considered to be included.

\section{Study selection}

Observational studies that met all of the following criteria were included: 1) Those that were case-control or cohort studies (no randomized controlled trials have been published to date); 2) Those that investigated the association between the use of any type of thiazides or thiazide combination medications for hypertension and the risk of skin cancers; and 3) Those that reported outcome measures with adjusted relative risk (aRR) or adjusted odds ratio (aOR) and 95\% confidence interval (CI) to consider confounding factors. Participants' age, gender, and underlying conditions were not considered during study selection. If more than one study shared the same study population, we included the study with the largest population or the longest follow-up.

\section{Data extraction and quality assessment}

Two experienced investigators (DS and ESL) independently examined the eligibility of all the studies extracted from the databases that met the study selection criteria. Any disagreements were resolved either via discussion or consultation with the other coauthors. The methodological quality of each of the studies was assessed by the two investigators based on the Newcastle-Ottawa Scale (NOS) [29]. The NOS of seven or more was considered as a good quality [30].

\section{Main and subgroup analyses}

In the main analysis, we investigated the association between overall use of thiazide diuretics and the risk of each type of skin cancers, including BCC, SCC, and MM. If a study did not report an aOR for overall use of thiazides, we first tried to contact authors. If there was no answer, we used that of hydrochlorothiazide (HCTZ) or HCTZ combination medications.
Subgroup meta-analyses were performed based on the types of thiazides, duration of thiazide use (long-term use), and study design (case-control or cohort study), because those factors might affect the risk of skin cancers. Use of thiazides more than 4.5 years was defined as a long-term use because included studies had used either 4.5 years or 5 years as a cut-off for long-term use. Among the various types of thiazides, we could only perform the subgroup meta-analysis on HCTZ or HCTZ combination medications due to lack of data for other types of thiazides. Similarly, the subgroup meta-analysis based on the duration of thiazide use was limited to the long-term use due to a lack of data for the short-term use. Furthermore, we could not perform subgroup analyses based on gender and individual risk factors on skin cancers, such as skin color, amount of sun exposure, or family history, due to a lack of data from the individual studies.

\section{Statistical analyses}

A pooled aOR with the $95 \%$ CIs was estimated from the aORs or aRRs and their 95\% CIs reported in the included studies. Since included studies were unlikely to be functionally equal and true effect size might differ between studies, we used random-effects model based on the DerSimonian-Laird method [31]. We assumed that the differences between the various measures of risk were not significant because the outcome of interest was sufficiently rare. Heterogeneity among the studies was evaluated using the Q-statistics (Q) with P value and Higgins $\mathrm{I}^{2}$ value [32]. Publication bias among the included studies was evaluated using the Begg's funnel plot and the Egger's test. Stata version 12.1 (StataCorp, College Station, TX, USA) was used for the statistical analysis.

\section{Results}

\section{Identification of relevant studies}

A flow diagram of study selection is demonstrated in Figure 1. A total of 4,341 articles were identified by searching three databases and manually searching relevant bibliographies. After excluding duplicate studies, we reviewed and excluded irrelevant studies based on their titles, abstracts, and full texts. In total, nine studies were included in the final analysis $[17,18$, 21-27]. Among the studies based on the Danish Cancer Registry and Civil Registration System [18, 20, 25], we included a study by Schmidt et al [25] in the main analysis, because it was the largest study with a longer period of follow-up. In the subgroup meta-analyses, however, we used results from a study by Jensen et al [18], because only their study provided the required data for the subgroup analyses. Recently, Pottegard et al [27] published another study based on the Danish Cancer Registry. Since its study population and study period did not overlap with those of the previous Danish studies, it was independently included in our meta-analysis. Friedman et al published two studies [19, 22] using the Kaiser Permanente Medical Care Program database and a more recent study with 


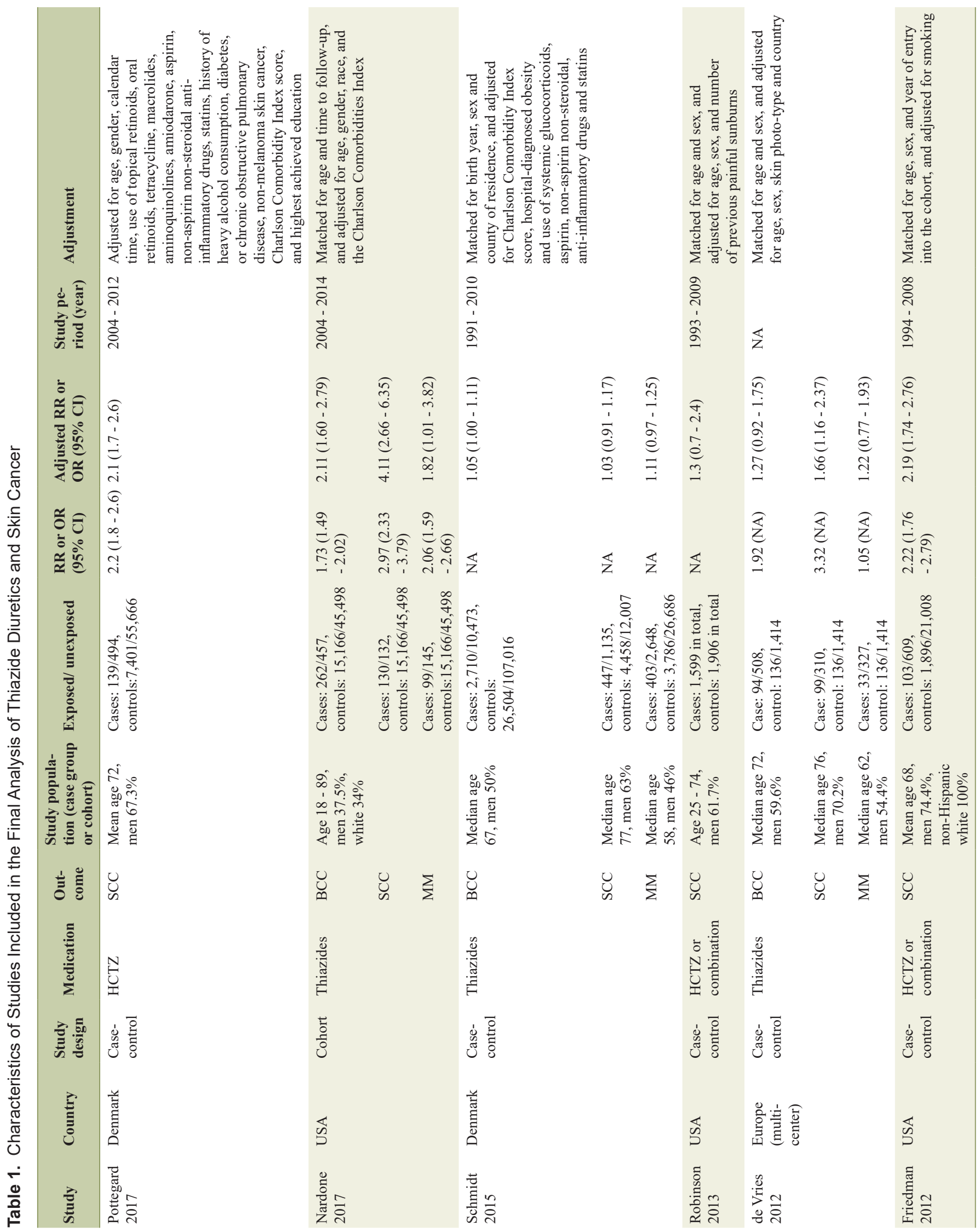




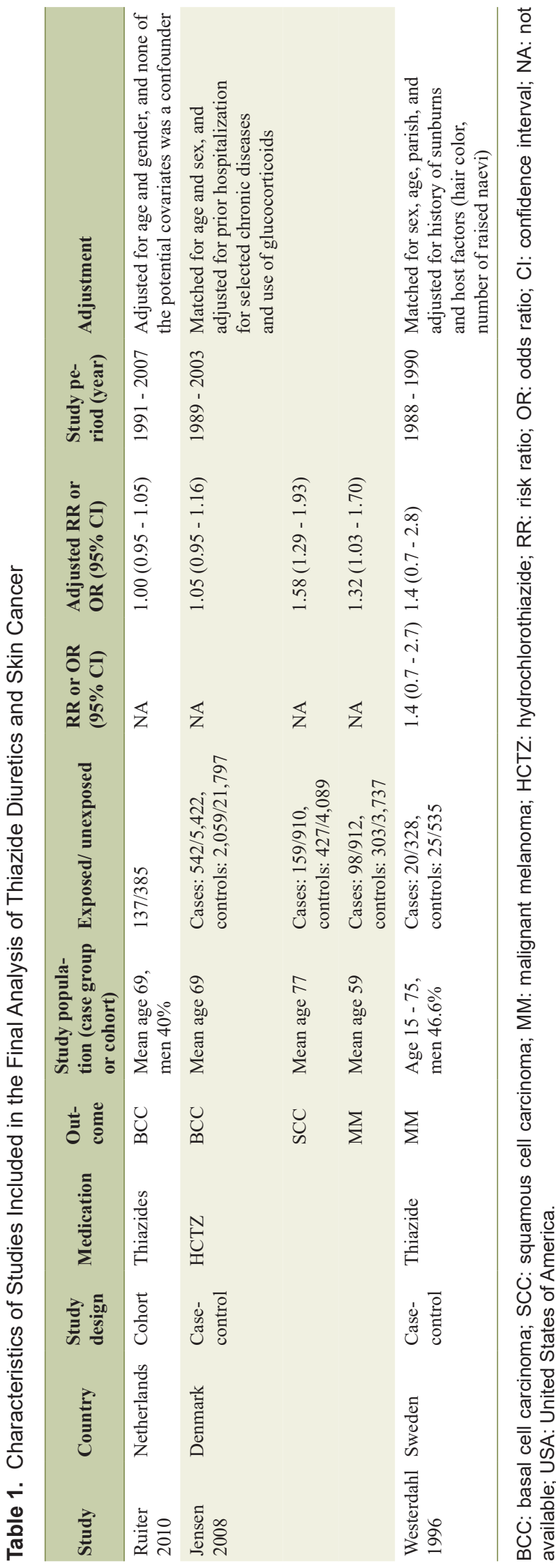

a longer follow-up [22] was included in our analysis.

\section{Characteristics of studies included in the analyses}

The descriptive data for the studies included in the meta-analysis are summarized in Table 1 [17, 18, 21-27]. We identified seven case-control studies [17, 18, 22-25, 27] and two cohort studies $[21,26]$. Five studies reported data for BCC $[18,21,23,25,26]$, seven studies for SCC [18, 22-27], and four studies for MM [17, 23, 25, 26]. Since SCC was a predominant type of skin cancer ( $97.2 \%$ of all cases) in a study by Friedman et al [22], their result was regarded as SCC's in this meta-analysis. Supplementary Table 2 demonstrated the methodological quality of the studies. The NOS was seven for all studies except one [27] whose score was 8 . The mean NOS was 7.1. Therefore, no study was excluded based on its quality.

\section{Main analysis}

In a random-effects meta-analysis of eight observational studies comprising 395,789 participants (Fig.2), we found a significant association between the use of thiazide diuretics and the risk of SCC (aOR, 1.86; 95\% CI, $1.23-2.80 ; \mathrm{I}^{2}=93.3 \%$; $\mathrm{Q}=75.1, \mathrm{P}<0.001)$. Also, there were marginally significant associations between the use of thiazides and the risk of $\mathrm{BCC}$ (aOR, 1.19; 95\% CI, $1.02-1.38 ; \mathrm{I}^{2}=89.6 \%$; Q $=28.8, \mathrm{P}<$ $0.001)$ and $\mathrm{MM}\left(\mathrm{aOR}, 1.14 ; 95 \% \mathrm{CI}, 1.01-1.29 ; \mathrm{I}^{2}=0.0 \%\right.$; $=2.5, \mathrm{P}=0.447)$.

\section{Subgroup meta-analysis}

\section{Types of thiazides}

In subgroup meta-analysis based on the types of thiazides, the use of HCTZ or HCTZ combination medications was associated with an increased risk of SCC without significant heterogeneity among studies (Fig. 3; aOR, 2.04; 95\% CI, 1.79 - 2.33; $\left.\mathrm{I}^{2}=0.0 \% ; \mathrm{Q}=2.7, \mathrm{P}=0.445\right)$. Pooled risk of $\mathrm{BCC}$ or $\mathrm{MM}$ in HCTZ or HCTZ combination medications users was not estimated, as only one study provided such data. In addition, this subgroup meta-analysis could not be done for other types of thiazides due to a lack of data.

\section{Other variables}

The rest of the results of subgroup meta-analyses according to the duration of use and study design are shown in Table 2 . The long-term use of thiazides ( $>4.5$ years) was significantly associated with an increased risk of SCC, but high heterogeneity was observed (aOR, 3.30; 95\% CI, 1.85 - 5.89.; $\mathrm{I}^{2}=90.7 \%$; $\mathrm{Q}=21.4, \mathrm{P}<0.001)$. For $\mathrm{BCC}$, there was no significant association between the long-term use of thiazides and the risk of $\mathrm{BCC}\left(\mathrm{aOR}, 1.10 ; 95 \% \mathrm{CI}, 0.96-1.25 ; \mathrm{I}^{2}=0.0 \%\right.$; $\mathrm{Q}=0.0$, 


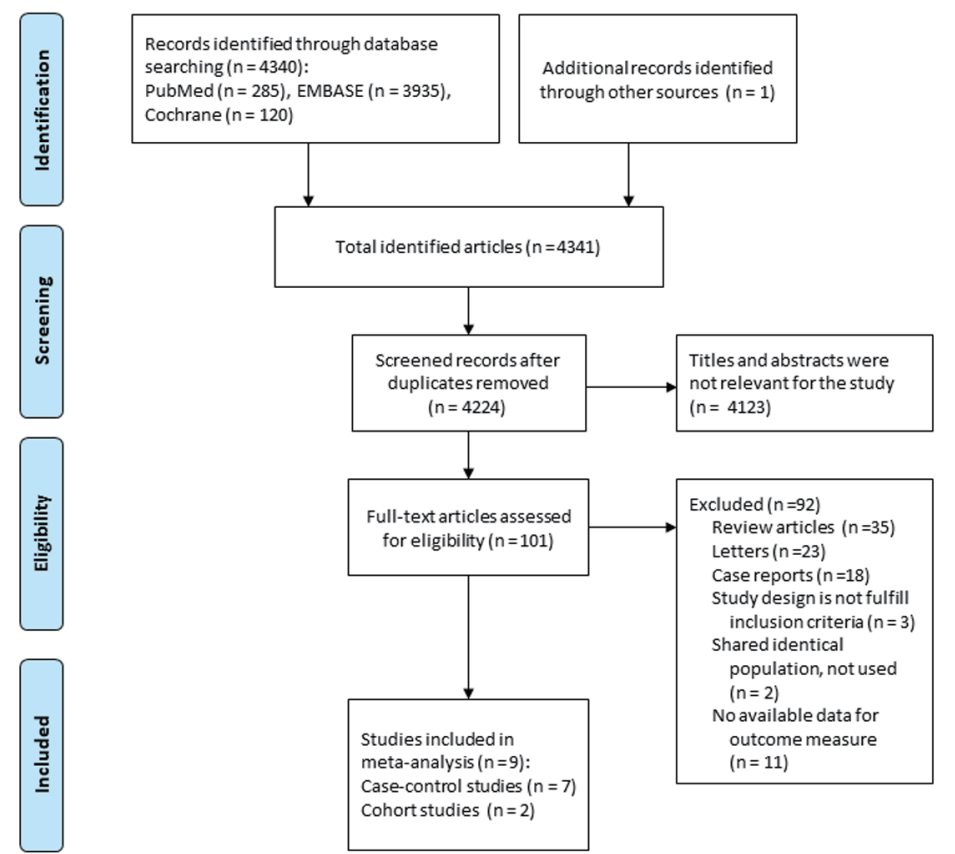

Figure 1. Flow diagram of studies identified and selected.

$\mathrm{P}=1.000)$. Not enough data for short-term thiazide users was available in the individual studies.

In the subgroup meta-analysis based on study design, there was no significant association between thiazide use and the risk of BCC. In contrast, there was only one cohort study for SCC and MM, and the overall results did not significantly change after excluding the cohort study.

\section{Publication bias}

Although asymmetries were observed on the funnel plots (Fig.

Table 2. Subgroup Analyses for Use of Thiazides and Risk of Skin Cancers Using Random-Effects Model

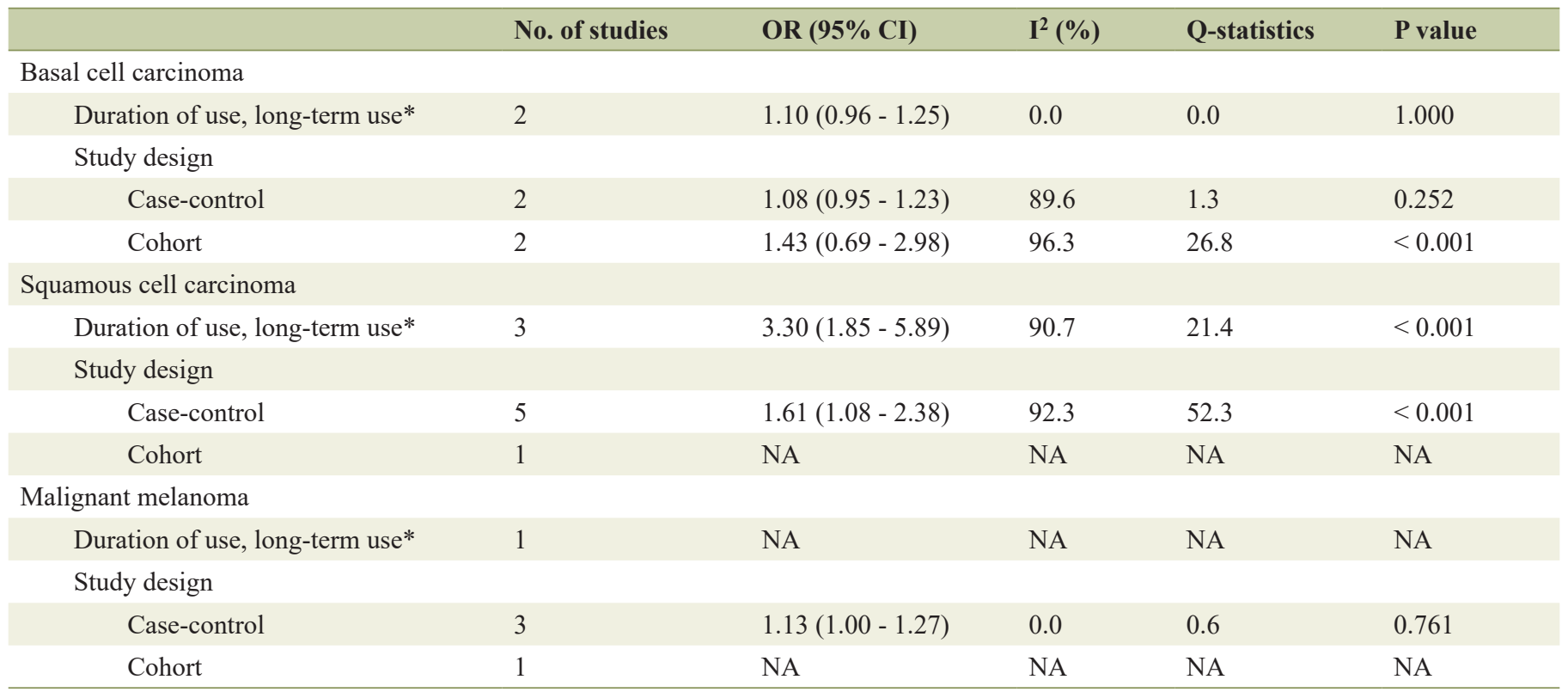

I2: Higgins score; NA: not available. *More than 4.5 years. 


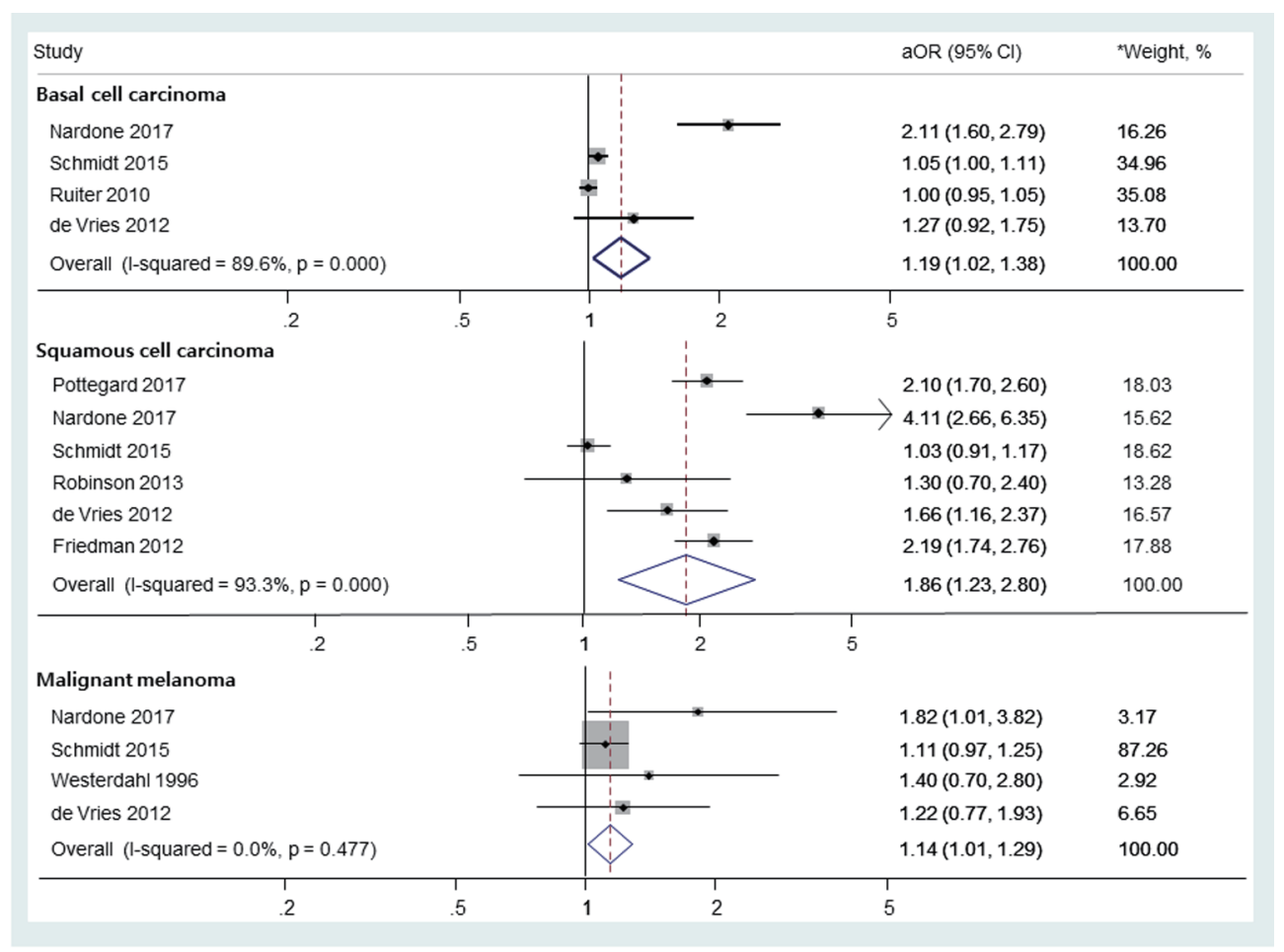

Figure 2. The risk of skin cancers among those who used thiazide diuretics. OR: odds ratio; RR: relative risk. *Weights are from random-effects analysis.

4), Begg's adjusted rank correlation tests did not show statistical significance $(\mathrm{P}$ for bias $=0.279$ for $\mathrm{BCC}, 0.851$ for $\mathrm{SCC}$, and 0.174 for $\mathrm{MM}$, respectively). Also, the $\mathrm{P}$ values for the bias from the Egger's test were not significant $(\mathrm{P}$ for bias $=$ 0.171 for $\mathrm{BCC}, 0.128$ for $\mathrm{SCC}$, and 0.109 for MM, respectively). However, due to small numbers of included studies, these results should be interpreted with caution and publication bias could not be fully excluded.

\section{Discussion}

In this meta-analysis of observational studies, we found significant association between the use of thiazide diuretics and the risk of SCC. There were marginally significant associations between thiazide use and the risk of BCC and MM. Especially,
HCTZ or HCTZ combination medications were significantly associated with an increased risk of SCC without significant heterogeneity among the studies. In a recent meta-analysis by Gandini et al [33], there was no significant association between thiazide diuretics and skin cancers. However, they only included six studies and pooled multiple estimates from one study that shared the same control groups. Furthermore, they did not differentiate types of skin cancers and did not perform subgroup analysis. These differences might result in the different results, and our study is by far the most updated and extensive meta-analysis on this topic.

Although the exact mechanism underlying the association between thiazides and skin cancers is unclear, the drugs' photosensitizing effect is thought to play a major role. Thiazides are sulfonamide-derived medications that can cause photosensitivity reaction [10, 34-36]. UV radiation induces dissociation

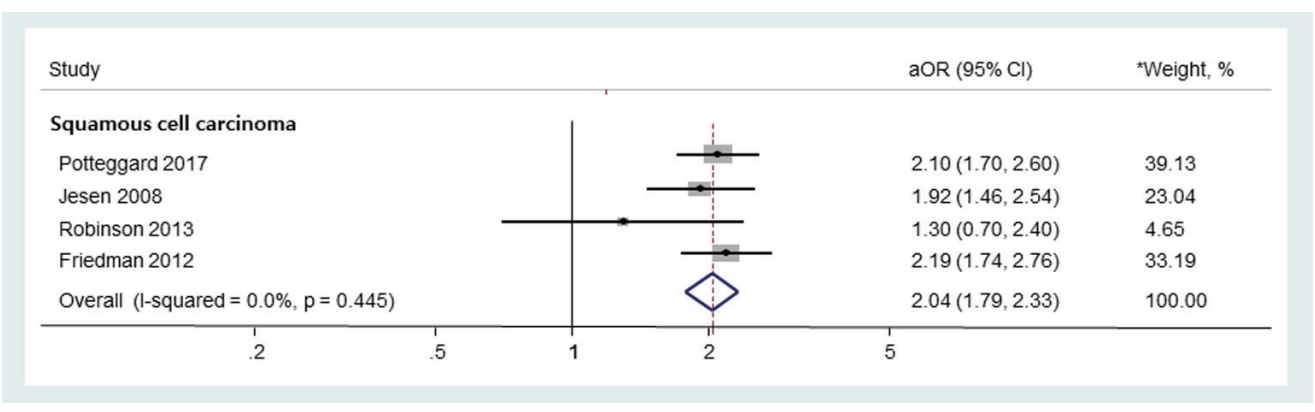

Figure 3. Subgroup meta-analysis on the use of HCTZ or HCTZ combination medications and the risk of skin cancers. HCTZ: hydrochlorothiazide; OR: odds ratio; RR: relative risk. *Weights are from random-effects analysis. 

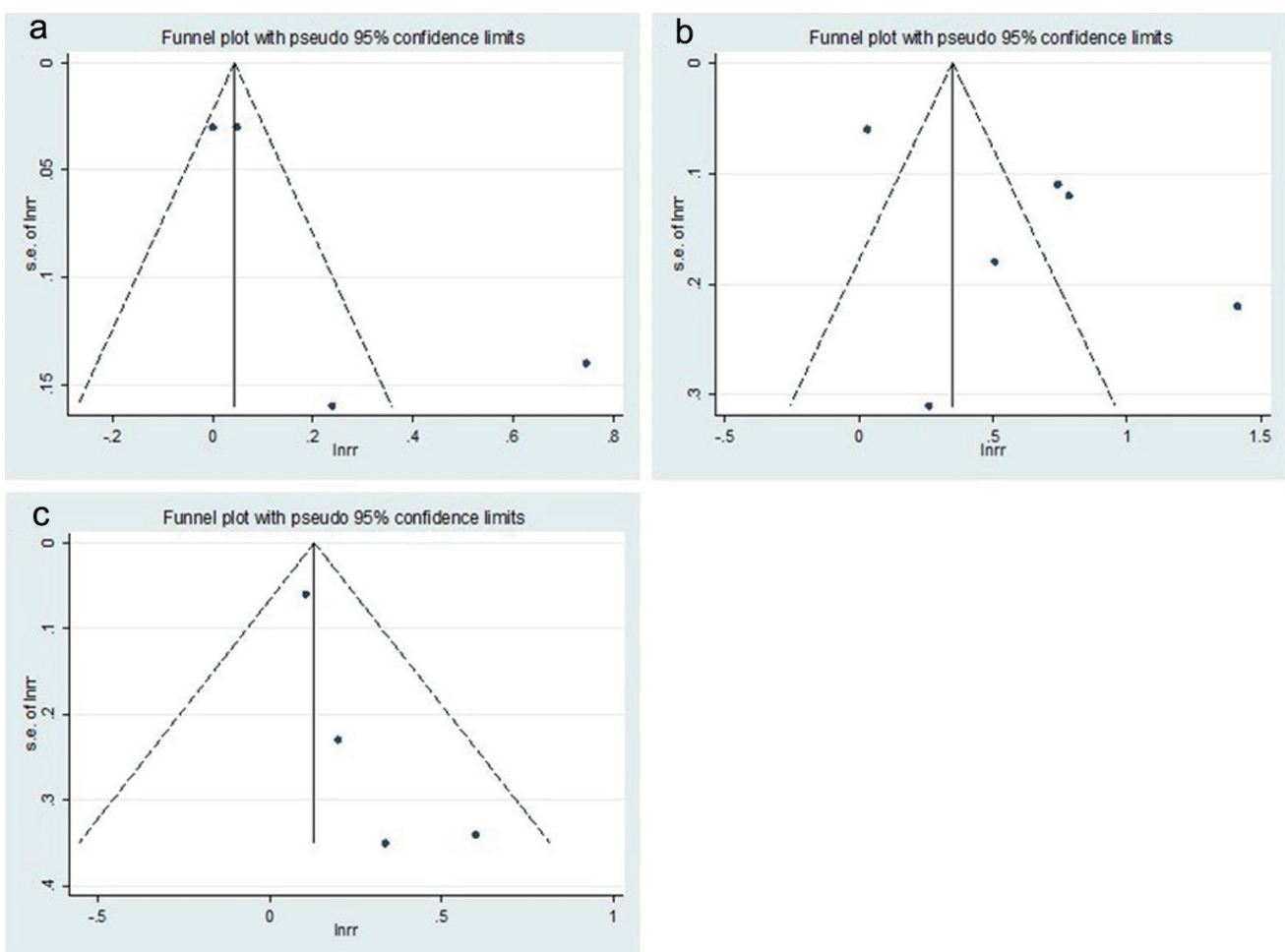

Figure 4. Funnel plots of studies for the use of thiazide diuretics and the risk of skin cancers. (a) Basal cell carcinoma, (b) squamous cell carcinoma, and (c) malignant melanoma.

of chlorine substituent of chemical structure of thiazides which causes free radical reaction and the formation of ROS [11-13]. These ROS induce damage to lipid membranes [37] and DNA [38]. In addition, a recent experimental study revealed that HCTZ significantly enhanced UV-A-induced DNA damage by stimulating production of thymine-thymine dimer and cyclobutane pyrimidine dimmers [39].Through these mechanisms, thiazide-induced photosensitivity could result in molecular and cellular damage leading to the skin cancers.

The photosensitization hypothesis is further supported by previous clinical observations of psoriasis patients treated with photochemotherapy (psoralens and UV-A (PUVA)). Several studies demonstrated that the drug-induced photosensitization of skin and subsequent exposure to UV radiation increased risk of skin cancers [14-16]. This increased risk was most pronounced for SCC and strongly related to the cumulative UV dose [40]. Our result was consistent with above findings in that the use of thiazides was most significantly associated with the risk of SCC among skin cancers. It was not surprising considering that the total sun exposure is known to be more strongly associated with SCC than other types of skin cancer [41]. However, further studies are required to validate this hypothesis.

In the subgroup meta-analysis based on the duration of medication use, long-term use of thiazides ( $>4.5$ years) was associated with an increased risk of SCC, but not BCC. Pooled risk of SCC among the long-term thiazide users was 1.7 times as high as that of overall thiazide users (aOR, 3.30 vs. 1.86, respectively). However, the pooled risk of skin cancers in long-term thiazides users could not be directly compared to that of short-term thiazide users due to a lack of available data. Furthermore, only a few case-control studies with potential recall-bias and significant heterogeneity were included in this subgroup analysis. Therefore, an exact impact of the duration of thiazides use on the risk of skin cancers could not be determined in our study. Since one study reported significantly increased risk of SCC with increasing duration of thiazide use [22], future studies on this topic should consider it as a possible effect modifier.

There are several limitations in our study. First, this metaanalysis only included observational studies in the absence of randomized controlled trials on this topic. This could result in a potential for bias and unaccounted confounders. To account for this limitation, only adjusted values were used in our metaanalysis. However, the cause-and-effect relationship between the use of thiazide diuretics and skin cancers could not be determined. Second, only a few studies were available per each type of skin cancers, which limited statistical power and did not allow more extensive subgroup analysis. Third, high heterogeneity among the studies for BCC or SCC was observed in the main analysis. Difference in types of thiazides might somewhat contribute to the high heterogeneity, but it was not enough to fully explain it. However, there was no significant heterogeneity among the studies when investigating the association between the use of HCTZ or HCTZ combination medications and the risk of SCC. Fourth, the impact of individual risk factors on skin cancers, such as skin color, amount of sun exposure, or family history, could not be fully considered in 
our meta-analysis due to a lack of data from the individual studies. Fifth, publication bias or other small study effects are possible. Although we searched three databases that are mostly commonly used in meta-analysis, not including more databases and excluding unpublished literatures could have contributed to the publication bias.

In conclusion, our results suggest that the use of thiazide diuretics may be associated with increased risk of skin cancers. Especially, this association was pronounced between the use of HCTZ or HCTZ combination medications and the risk of SCC. Further studies are needed to confirm these findings.

\section{Acknowledgments}

None.

\section{Funding}

The authors received no financial support for the research, authorship, and/or publication of this article.

\section{Conflict of Interest}

The authors declare that they have no conflict of interest.

\section{References}

1. Mills KT, Bundy JD, Kelly TN, Reed JE, Kearney PM, Reynolds K, Chen J, et al. Global disparities of hypertension prevalence and control: a systematic analysis of population-based studies from 90 countries. Circulation. 2016;134(6):441-450.

2. James PA, Oparil S, Carter BL, Cushman WC, Dennison-Himmelfarb C, Handler J, Lackland DT, et al. 2014 evidence-based guideline for the management of high blood pressure in adults: report from the panel members appointed to the Eighth Joint National Committee (JNC 8). JAMA. 2014;311(5):507-520.

3. Cognetta AB, Jr., Wolfe CM, Heinrichs E. Hydrochlorothiazide Use and Skin Cancer: A Mohs Surgeon's Concern. Dermatol Surg. 2016;42(9):1107-1109.

4. Stafford RS, Monti V, Furberg CD, Ma J. Long-term and short-term changes in antihypertensive prescribing by office-based physicians in the United States. Hypertension. 2006;48(2):213-218.

5. Gu Q, Burt VL, Dillon CF, Yoon S. Trends in antihypertensive medication use and blood pressure control among United States adults with hypertension: the National Health And Nutrition Examination Survey, 2001 to 2010. Circulation. 2012;126(17):2105-2114.

6. Stern RS. Prevalence of a history of skin cancer in 2007: results of an incidence-based model. Arch Dermatol. 2010;146(3):279-282.

7. Rogers HW, Weinstock MA, Feldman SR, Coldiron BM.
Incidence estimate of nonmelanoma skin cancer (Keratinocyte Carcinomas) in the U.S. population, 2012. JAMA Dermatol. 2015;151(10):1081-1086.

8. Guy GP, Jr., Machlin SR, Ekwueme DU, Yabroff KR. Prevalence and costs of skin cancer treatment in the U.S., 2002-2006 and 2007-2011. Am J Prev Med. 2015;48(2):183-187.

9. Robinson HN, Morison WL, Hood AF. Thiazide diuretic therapy and chronic photosensitivity. Arch Dermatol. 1985;121(4):522-524.

10. Gomez-Bernal S, Alvarez-Perez A, Rodriguez-Pazos L, Gutierrez-Gonzalez E, Rodriguez-Granados MT, Toribio J. Photosensitivity due to thiazides. Actas Dermosifiliogr. 2014;105(4):359-366.

11. Zuba EB, Koronowska S, Osmola-Mankowska A, Jenerowicz D. Drug-induced photosensitivity. Acta Dermatovenerol Croat. 2016;24(1):55-64.

12. Ferguson J. Drug-induced photosensitivity. In: Ferguson J, Dover JS, eds. Photodermatology. London: Manson Publishing, 2006: p. 72-80.

13. Moore DE. Drug-induced cutaneous photosensitivity: incidence, mechanism, prevention and management. Drug Saf. 2002;25(5):345-372.

14. Stern RS, Study PF-U. The risk of squamous cell and basal cell cancer associated with psoralen and ultraviolet A therapy: a 30-year prospective study. J Am Acad Dermatol. 2012;66(4):553-562.

15. Lindelof B, Sigurgeirsson B, Tegner E, Larko O, Johannesson A, Berne B, Ljunggren B, et al. PUVA and cancer risk: the Swedish follow-up study. Br J Dermatol. 1999;141(1):108-112.

16. Stern RS, Study PFu. The risk of melanoma in association with long-term exposure to PUVA. J Am Acad Dermatol. 2001;44(5):755-761.

17. Westerdahl J, Olsson H, Masback A, Ingvar C, Jonsson $\mathrm{N}$. Risk of malignant melanoma in relation to drug intake, alcohol, smoking and hormonal factors. Br J Cancer. 1996;73(9):1126-1131.

18. Jensen AO, Thomsen HF, Engebjerg MC, Olesen AB, Sorensen HT, Karagas MR. Use of photosensitising diuretics and risk of skin cancer: a population-based casecontrol study. Br J Cancer. 2008;99(9):1522-1528.

19. Friedman GD, Udaltsova N, Chan J, Quesenberry CP, Jr., Habel LA. Screening pharmaceuticals for possible carcinogenic effects: initial positive results for drugs not previously screened. Cancer Causes Control. 2009;20(10):1821-1835.

20. Kaae J, Boyd HA, Hansen AV, Wulf HC, Wohlfahrt J, Melbye M. Photosensitizing medication use and risk of skin cancer. Cancer Epidemiol Biomarkers Prev. 2010;19(11):2942-2949.

21. Ruiter R, Visser LE, Eijgelsheim M, Rodenburg EM, Hofman A, Coebergh JW, Nijsten T, et al. High-ceiling diuretics are associated with an increased risk of basal cell carcinoma in a population-based follow-up study. Eur J Cancer. 2010;46(13):2467-2472.

22. Friedman GD, Asgari MM, Warton EM, Chan J, Habel LA. Antihypertensive drugs and lip cancer in non-Hispanic whites. Arch Intern Med. 2012;172(16):1246-1251. 
23. de Vries E, Trakatelli M, Kalabalikis D, Ferrandiz L, Ruiz-de-Casas A, Moreno-Ramirez D, Sotiriadis D, et al. Known and potential new risk factors for skin cancer in European populations: a multicentre case-control study. Br J Dermatol. 2012;167(Suppl 2):1-13.

24. Robinson SN, Zens MS, Perry AE, Spencer SK, Duell EJ, Karagas MR. Photosensitizing agents and the risk of nonmelanoma skin cancer: a population-based case-control study. J Invest Dermatol. 2013;133(8):1950-1955.

25. Schmidt SA, Schmidt M, Mehnert F, Lemeshow S, Sorensen HT. Use of antihypertensive drugs and risk of skin cancer. J Eur Acad Dermatol Venereol. 2015;29(8):15451554.

26. Nardone B, Majewski S, Kim AS, Kiguradze T, MartinezEscala EM, Friedland R, Amin A, et al. Melanoma and non-melanoma skin cancer associated with angiotensin-converting-enzyme inhibitors, angiotensin-receptor blockers and thiazides: a matched cohort study. Drug Saf. 2017;40(3):249-255.

27. Pottegard A, Hallas J, Olesen M, Svendsen MT, Habel LA, Friedman GD, Friis S. Hydrochlorothiazide use is strongly associated with risk of lip cancer. J Intern Med. 2017;282(4):322-331.

28. Stroup DF, Berlin JA, Morton SC, Olkin I, Williamson GD, Rennie D, Moher D, et al. Meta-analysis of observational studies in epidemiology: a proposal for reporting. Meta-analysis Of Observational Studies in Epidemiology (MOOSE) group. JAMA. 2000;283(15):2008-2012.

29. Wells G SB, O'Connell D, Peterson J, Welch V, Losos M, Tugwell P. The newcastle-ottawa scale (NOS) for assessing the quality of nonrandomised studies in meta-analyses. 2011. Available from: http://www.ohri.ca/programs/ clinical_epidemiology/oxford.asp.

30. Hartling L, Hamm M, Milne A, Vandermeer B, Santaguida PL, Ansari M, Tsertsvadze A, et al. In: Validity and Inter-Rater Reliability Testing of Quality Assessment Instruments. Rockville (MD), 2012.

31. DerSimonian R, Laird N. Meta-analysis in clinical trials. Control Clin Trials. 1986;7(3):177-188.
32. Higgins JP, Thompson SG, Deeks JJ, Altman DG. Measuring inconsistency in meta-analyses. BMJ. 2003;327(7414):557-560.

33. Gandini S, Palli D, Spadola G, Bendinelli B, Cocorocchio E, Stanganelli I, Miligi L, et al. Anti-hypertensive drugs and skin cancer risk: a review of the literature and metaanalysis. Crit Rev Oncol Hematol. 2018;122:1-9.

34. Selvaag E, Thune P. Phototoxicity to sulphonamide-derived oral antidiabetics and diuretics: investigations in hairless mice. Photodermatol Photoimmunol Photomed. 1997;13(1-2):4-8.

35. Addo HA, Ferguson J, Frain-Bell W. Thiazide-induced photosensitivity: a study of 33 subjects. Br J Dermatol. 1987;116(6):749-760.

36. Sica DA. Diuretic therapy in cardiovascular disease. In: Black HR, Elliott WJ, eds. Hypertension: A companion to Braunwald's Heart Disease. 2nd ed. Philadelphia: Saunders, 2012: p. 169-170.

37. Matsuo I, Fujita H, Hayakawa K, Ohkido M. Lipid peroxidative potency of photosensitized thiazide diuretics. J Invest Dermatol. 1986;87(5):637-641

38. Selvaag E, Petersen AB, Gniadecki R, Thorn T, Wulf HC. Phototoxicity to diuretics and antidiabetics in the cultured keratinocyte cell line $\mathrm{HaCaT}$ : evaluation by clonogenic assay and single cell gel electrophoresis Comet assay). Photodermatol Photoimmunol Photomed. 2002;18(2):9095.

39. Kunisada M, Masaki T, Ono R, Morinaga H, Nakano E, Yogianti F, Okunishi K, et al. Hydrochlorothiazide enhances UVA-induced DNA damage. Photochem Photobiol. 2013;89(3):649-654.

40. Archier E, Devaux S, Castela E, Gallini A, Aubin F, Le Maitre M, Aractingi S, et al. Carcinogenic risks of psoralen UV-A therapy and narrowband UV-B therapy in chronic plaque psoriasis: a systematic literature review. J Eur Acad Dermatol Venereol. 2012;26(Suppl 3):22-31.

41. Armstrong BK, Kricker A. The epidemiology of UV induced skin cancer. J Photochem Photobiol B. 2001;63(13):8-18. 